\title{
Fronteras: Espacios de sociabilidad en la Santa Marta de mediados del XVIII en Colombia
}

\section{Borders: Spaces of sociability in Santa Marta in the mid-eighteenth century in Colombia}

David Jerónimo Luquetta Cedie/*

\section{Resumen}

El proceso de establecimiento de fronteras fijas en territorios sin dominio político estable por parte de un Estado, en este caso el Estado Monárquico, antes que ordenar el territorio produce un fenómeno totalmente distinto. La creación de sociedades mestizas, en el norte de lo que hoy es Colombia, es un proceso que encuentra sus raíces en la implementación de las Reformas Borbónicas a mediados del XVIII por parte de los agentes de la Corona. Este artículo pretende reconocer y comprender los procesos que dieron paso al surgimiento de una sociedad autónoma en esta área de frontera.

Palabras clave: frontera, sociabilidad, mestizaje, transformación cultural, negociación.

\begin{abstract}
When a state, in this case a monarchical state, establishes fixed borders in territories without a stable political domain, the result is completely different than that of organizing such a territory. The creation of mixed societies in the north of present-day Colombia is a process whose roots are found in the implementation of the Bourbon Reforms in the mid-eighteenth century by Crown Agents. This article identifies and discusses the processes that led to the emergence of an autonomous society in this border area.

Keywords: border, sociability, mestizaje, cultural transformation, negotiation.
\end{abstract}

Recibido: 23 de enero de 2015.

Aprobado: 1 de octubre de 2015.

* Universidad Autónoma del Caribe. Dirección: Calle 90. núm. 46. Barranquilla, Colombia.Correo electrónico: dluquetta@hotmail.com y david.luqueta@uac.edu.co 


\section{Introducción}

El propósito del presente texto es comprender cómo la configuración social de un territorio está ligada a las dinámicas poblacionales que se gestan en el mismo, teniendo como elemento clave el establecimiento de fronteras, a través de la fundación de pueblos y reducciones. Para el caso concreto se centra el interés en la provincia de Santa Marta a mediados del xviII, ubicada al norte de lo que hoy es Colombia. Particularizo en esta época por lo que es el momento en que la Corona española inicia el proceso de reorganización de este territorio bajo las orientaciones de las Reformas Borbónicas.

El mismo fenómeno se vive en esta época en todo el territorio continental. Al respecto dice Lía Quarleri "En las últimas décadas del siglo XVIII, el espacio hispanoamericano vivió un conjunto intenso de movimientos poblacionales y trasformaciones demográficas producto de políticas directas, incentivadas por determinados marcos ideológicos, así como de transformaciones socio/económicas" (Quarleri, 2012, párr. 1).

Esta región estaba habitada por sociedades que se vieron afectadas desde el contacto por el proceso de occidentalización que impuso el imperio español. Como resultado de este fenómeno logramos ubicar dos categorías amplias de sociedades, por una parte los pueblos aborígenes denominados "indios pacíficos" que se sometieron e iniciaron una adaptación al nuevo sistema social, transformando su cultura (Gutiérrez, 2010; Gruzinski, 2004). Por otra, los pueblos que se resistieron a la dominación, llamados estos "indios no conquistados" o "salvajes" que se opusieron a las imposiciones del sistema colonial, por lo que se convirtieron en objetivos de acciones militares para los representantes de la Corona (Zuluaga, 2010).

Con el paso del tiempo, a este territorio, también llegaron comunidades de individuos libres de todos colores, mestizos, mulatos, zambos, incluso españoles fugitivos, que se asimilaron a las mismas dinámicas que, sin ser el propósito, iniciaron la implementación de las reformas borbónicas y el surgimiento de una nueva sociedad. Se trató de una sociedad marginal que supo adaptarse a las condiciones que la naturaleza les brindó, resultando en un proceso de mestizaje social que configuró una población dispersa en este territorio, pero muy arraigada al mismo. 
El territorio que he venido mencionando se sitúa más allá de las fronteras de los españoles al norte del Virreinato de Nueva Granada, más específicamente se trata de la selva interfluvial que se extiende entre los ríos Cesar al este y Magdalena al oeste; la Depresión Momposina al sur y al norte hasta la Ciénaga Grande y Sierra Nevada de Santa Marta (ReichelDolmatoff, 1946). Fue un territorio selvático habitado por pueblos precolombinos sometidos a procesos de poblamientos, intercambios culturales materiales e inmateriales y al intento por parte de la Corona de establecer fronteras fijas y un dominio perceptible y eficaz. Esta área, es la que denomina Viviana García como área de frontera, que se refiere al territorio adyacente a los límites donde todas las relaciones de sociabilidad se gestan (García, 2015). Estas fronteras antes que dominar, se convirtieron en lugares difusos, poco claros, con retrocesos y avances continuos; más bien en lugares de negociación y sociabilidad de todos los grupos que cohabitaban a lo largo de todo el territorio.

El proyecto de poblamiento de la Corona consistía en fundar pueblos a lo largo de los ríos de la región, con mayor interés en las márgenes del río Magdalena, por ser la arteria fluvial comercial más importante del virreinato, con el objetivo de delimitar, controlar y proteger los cargamentos que navegaban de los ataques de la población no conquistada que intentaban sabotear los intereses de la Corona (Ybot, 1952). Al mismo tiempo, se iba implementando un control fiscal y económico a todo el comercio informal que se había estructurado en la depresión Momposina. Así mismo, la intención era ordenar toda la población dispersa que habitaba la selva, para adoctrinarlos, reducirlos, evangelizarlos y por supuesto: utilizarlos como mano de obra para actividades mineras y agropecuarias. Sin embargo, afirma Eugenia Néspolo, que antes que implicar mayor control social, lo que resultó del dinamismo de las fronteras fue la configuración de una sociedad mestiza donde participaron todos los habitantes de estas tierras (Néspolo, 2006; Quarleri, 2012).

Tal y como dice Jorge Conde (1999) refiriéndose a la provincia de Cartagena:

Este modelo de organización espacial fue espontáneo y disperso y ocurrió por fuera del control de la ciudad colonial Cartagena de indias. Pero al mismo tiempo el desplazamiento de la población mestiza hacia esos espacios vacíos 
señaló la existencia de unas fronteras agrarias susceptibles de nuevos asentamientos conocidos como sitios (pp. 34-35).

Este fenómeno se replicó por toda la región del Caribe (Polo, 2007). Para la Corona y la Iglesia estos sitios se convirtieron en una constante amenaza para la estabilidad social, puesto que era el lugar propicio para el surgimiento de la cultura mestiza.

Estas tierras atraían a la Corona y los criollos que gobernaban desde las plazas mayores, por sus condiciones idóneas para el cultivo y ganadería (Rosa, 1975). Sin embargo, tanto la selva como las ciudades principales, entre ellas Mompox, siendo uno de los sitios fronterizos del poder colonial, estaban habitadas por gente de todo género (Santa Gertrudis, 1970).

Particularmente Mompox estaba ubicada en una posición estratégica para el comercio formal e informal, dado que era paso obligado para quienes traían maderas, resinas, oro, plata, pieles, del sur del virreinato a los puertos del Mar Caribe para su exportación o comercialización. También era el cruce por donde pasaban las mercancías que entraban legalmente por los puertos autorizados en la época, Santa Marta, Cartagena, Portobelo; pero también de contrabando de los ingleses y holandeses por Riohacha hacia el sur (Trejos y Luquetta, 2014). Dice Salzedo del Villar (1987) que Mompox logró adquirir un estatus comercial convirtiéndose en el núcleo comercial de la provincia (Herrera, 2002) "Su comercio era considerable y activo; no errando en decir que era la segunda plaza comercial de la Colonia" (p. 75). Del mismo modo lo afirma Fals Borda (1979), "Mompox sobresalía entonces como centro natural del contrabando de importación" (p. 87A). Por esta villa tenía que pasar obligatoriamente toda la mercancía que venía de Honda, Ocaña, de las minas del sur de la provincia de Cartagena y del norte de Antioquia (Humboldt, 1980). Razón por la que toda esta región le significó adquisición de grandes extensiones de tierra y a su vez riquezas a los marquesados (Daza, 2009).

\section{Poblamiento en el XVIII}

En un primer momento, la Corona designó a Don José Fernando de Mier y Guerra, un noble español, sobrino del primer Marqués de Santa 
Coa, radicado en Mompox, para que lograra cumplir todo lo que prometía la implementación de las reformas. Mier y Guerra, por su título de maestre de campo de toda la provincia, estuvo revestido de poder judicial otorgado por el Virrey Eslava, a quien también resultaba beneficioso, puesto que el mismo pacificador costeó las campañas y entradas. Como complemento, el Estado le permitía impartir justicia para legitimar el sistema y ordenar, teniendo el control de todos los resortes para control de la situación. En contra posición también se detecta una fuerte presencia de actividad comercial proveniente del contrabando, ${ }^{1}$ del cual el mismo Mier y Guerra y otros representantes de la Corona se lucraban. "Fue tan grande esta simbiosis que nadie, en esa sociedad, pudo lavarse las manos, en una cadena de connivencia que llegó, como en tiempos más actuales, a los más altos niveles de la administración” (Fals, 1979, p. 87A).

La labor que Mier y Guerra llevó a cabo significó la fundación de 12 pueblos ubicados casi todos en la margen derecha del Magdalena en una primera etapa que le tomó cuatro años (ver figura 1). En este tiempo, el pacificador trató de establecer el orden social que pretendía la Corona, sin embargo lo que sustenta este texto, es que más allá de controlar, lo que impulsó fue que la población que era el objetivo de las campañas o entradas, se replegara hacia el monte o selva e iniciara un nuevo ordenamiento social y cultural totalmente autónomo, por fuera de la vigilancia y control de la Corona y la Iglesia (ver figura 2).

El objetivo fue establecer un modelo de administración territorial basado en la apropiación del territorio que por natural derecho los nativos usufructuaban y por los que andaban libremente. La intención era satisfacer la necesidad de la Corona por desplegar sus dominios más allá de los pequeños espacios que había logrado acaparar, al mismo tiempo que expandir sus fronteras (Luquetta y Vidal, 2014).

Después de la muerte de Mier y Guerra, en 1780 asumió el cargo de maestre el que fuera capitán de conquista, Agustín de la Sierra. En este período se provoca una nueva ola de poblaciones (González, 1978), estas son: Garupal (Misioneros Capuchinos); San Miguel de Punta Gorda (Misioneros Capuchinos); Santa Catalina; San Antonio (Misioneros Capuchinos); Ariguaní; Concepción de Venero; y San José de las Pavas (Misioneros

${ }^{1}$ Para profundizar, revisar a: Polo, J. y Solano, S. (2011); Polo, J. (2005); Grahn, R. (1985); Pedraja, R. de la (1978) y García, A. (2011). 
Figura 1. Fundaciones de José Fernando de Mier y Guerra (1749-1753)

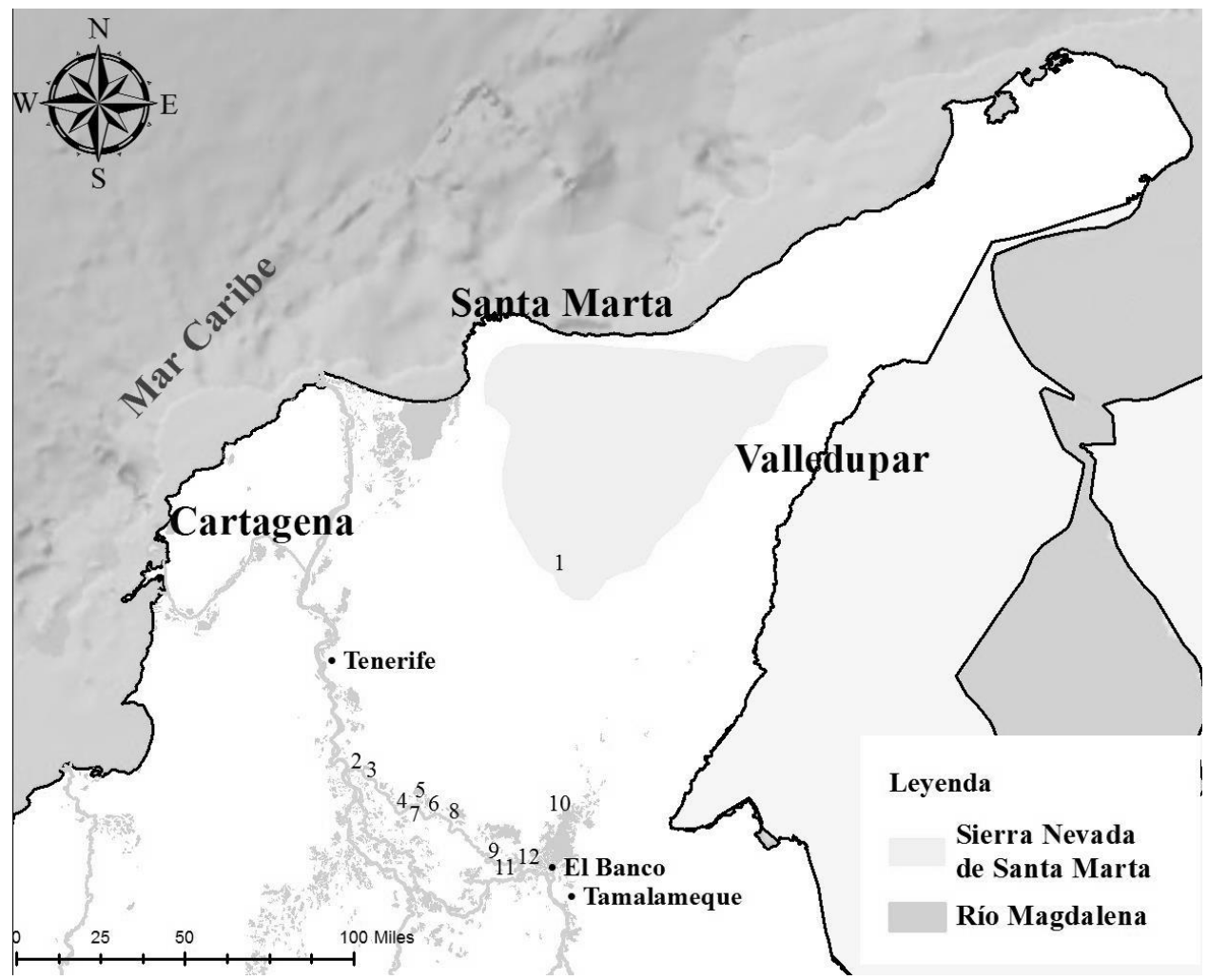

1. San Sebastián de Rábago

2. Santa Ana de Pinto

3. Nuestra Señora de Barrancas

4. Santa Ana de Buenavista

5. San Fernando del Cascajal

6. San Zenón de Navarro
7. Santa Cruz de Pizarro

8. San Sebastián de Menchiquejo

9. Carvajal

10. Chimichaque

11. Candelaria

12. Tamalamequito

Fuente: Elaboración propia. 


\section{Figura 2. Expedición de 1764 liderada por Mier y Guerra en compañía de Antonio Alcoy}

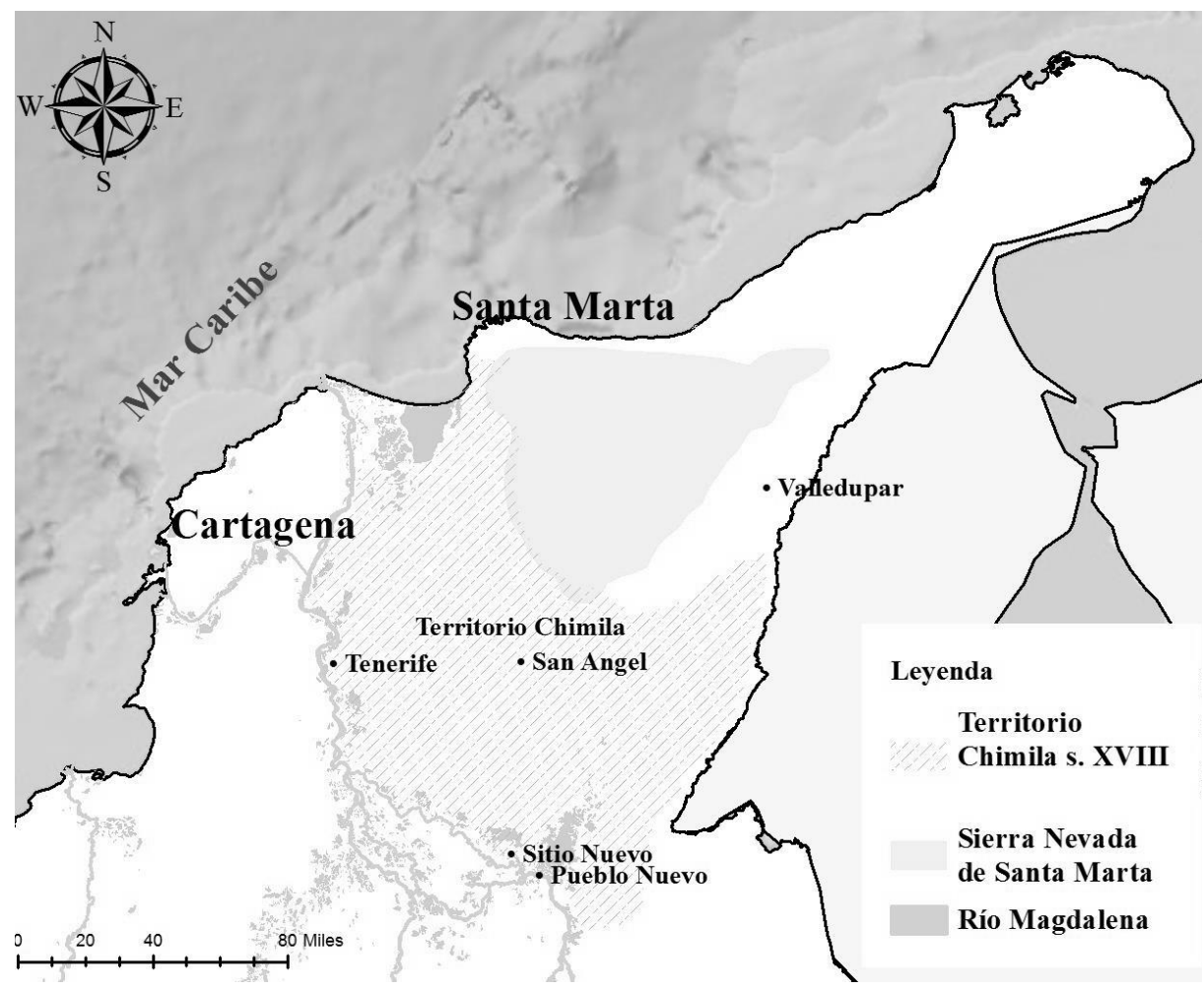

Fuente: Elaboración propia.

Capuchinos) Véase la figura 3. El nombramiento de Agustín de la Sierra, se lleva a cabo por haber prestado sus servicios como capitán de conquista del maestre de campo Mier y Guerra por los lados de Valledupar. Fue un militar que había adquirido una vasta experiencia en la contención de los indios Chimila.

$\mathrm{Al}$ mismo tiempo que los pobladores trataban de tomar posesión de los territorios marginales, los religiosos también intentaban cumplir sus labores evangelizadoras. De esta manera se incluye un nuevo actor al paisaje 
Figura 3. Fundaciones de Agustín de la Sierra (1776)

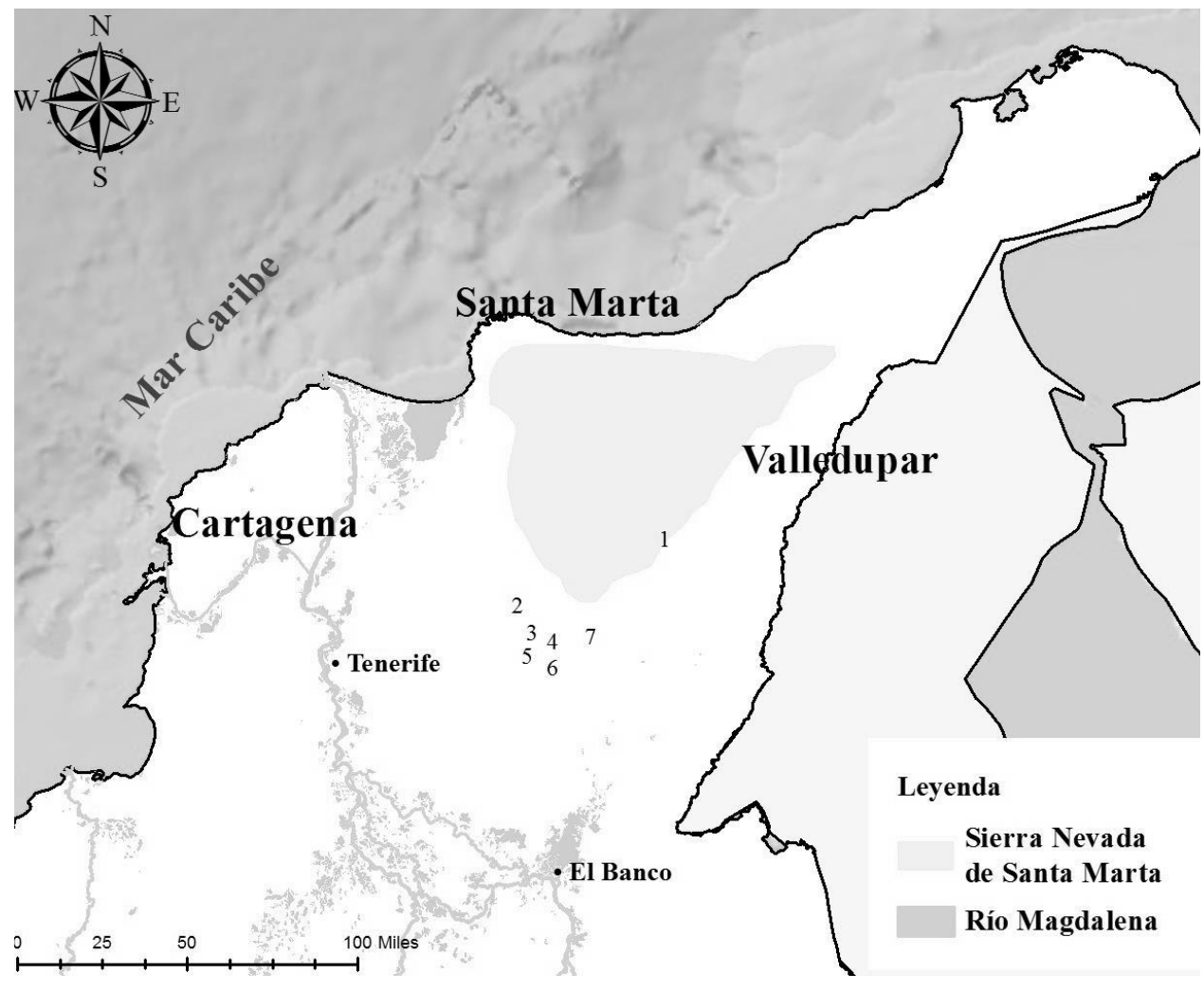

1. Garupal

2. San Miguel de Punta Gorda

3. Santa Catalina

4. San Antonio
5. Ariguaní

6. Concepción de Venero

7. San José de las Pavas

Fuente: Elaboración propia. 
social que había venido configurándose. Así como los colonizadores representaban una cultura, los misioneros y otros representantes de la Iglesia también incluyeron otros aspectos culturales propios. Esta situación creó nuevas formas de territorialidad, dado que asimilando o negando la evangelización, los habitantes de la selva sintieron la influencia de este vaivén de elementos culturales materiales e inmateriales. La fundación de los pueblos, no sólo consistía en ponerle nombre a un espacio, sino también insertar prácticas agrícolas, pecuarias, herramientas, incluso una nueva forma de percibir el tiempo.

A los nativos y mestizos que se asentaban en los pueblos fundados por los colonizadores, les daban herramientas para tumbar y cultivar el monte, así como animales para criar. Por su parte, los no conquistados, continuaban con sus prácticas culturales (Sæther, 2005). De la misma forma que iban a los pueblos a recibir los beneficios, volvían a la selva para continuar con sus formas de vida tradicionales.

Si para dicho acopio de familias se dispensará a cada una lo que el señor Narváez pedía para cada indio es dos vacas, doce cabras, once gallinas y un gallo, un machete y una hacha, $[\ldots]$ y debe celar para que estos con el motivo o con el de salir del pueblo con el pretexto de que vienen a buscar sus provisiones para mantenerse: pan, vino y cera, se disculpan y cuando se les obliga a que vayan a cumplir con sus obligaciones con manifestar enfermedades ciertas o supuestas dejan burladas sus esperanzas abandonados sus feligreses (Archivo General de la Nación Colombia [AGN], 1797-1798).

\section{Mestizaje en áreas de frontera}

En la selva, los libres convivían con toda la población que habitaba en el territorio. De tal manera que fueron creando alianzas para resistir las entradas de los españoles y atacar los convoyes de mercancías que transitaban por tierra y río. Como respuesta a las entradas de la Corona, los habitantes de los valles interfluviales, se sintieron resguardados en las grandes extensiones de selva que estaban por fuera del dominio de los reyes católicos. 
Con la implementación de las reformas, las campañas se hicieron cada vez más intensas y menos eludibles, así como el proceso de transformación cultural. Razón por la que cada vez se fueron creando alianzas más fuertes y estructuradas al interior de la selva para crear una fuerza social que obstaculizara el paso y llegada de la cultura ibérica. Este grupo, fue objeto de ataques para buscar su pacificación o reducción de manera repetitiva como se evidencia con los testimonios de la época. Al igual que los que se sometieron, las parcialidades que buscaron salvaguardar su territorio, sus prácticas rituales, su religión, su cultura, se vieron envueltos en una serie de fenómenos de mestizaje que se generó a partir de alianzas en defensa del territorio, entre otras, los Chimilas con los Arauacos, Taironas, Goajiros (Isaacs, 1951) y con el pasar del tiempo con toda la población libre de todos colores y mestizos (Sæther, 2005).

El mestizaje, promovido en un primer momento por dichas alianzas, se había acrecentado en estas selvas donde convivían nativos con mestizos y posiblemente españoles fugitivos de la ley. ${ }^{2}$ En diversos testimonios de distintos momentos de la época, se permite afirmar cómo, era en una atómica escala, la configuración social de toda la selva de la Provincia.

Eran setenta los Indios Chimilas, pero venia de capitan, ó bárbaro jefe de ellos, un mestizo, y viendo que nosotros habíamos escapado de sus manos, desfogaron su rabia con los pobres negros de la hacienda [...] Este caso prueba que los Chimilas tienen en los pueblos espías que les avisan y les dan solo de los pasajeros: prueba que no son solos en aquellas tierras de bárbaros los Chimilas, y como se apareció con ellos aquel mestizo que los dirigía, quizás hay otros mestizos y negros; y quiera Dios que no haya algún blanco fugitivo de la justicia, y refugiado entre aquellos bárbaros (Julián, 1854, p. 162).

... Me salieron una partida de indios de nación chimila que tenían al parecer el número de 30 porque me pusieron en bastante confusión por discurrirme algún insulto, hasta que hablandome uno entre ellos civilizado que al fin me dijo que se llamaba Manuel José de la Sierra y haciendome los más incoherentes expresiones me hizo ver que en aquel lugar donde se hallaban acogi-

${ }^{2}$ Retomamos el concepto de convivir de Julio Caro Baroja en el que se piensa en el dinamismo que se crea al momento del choque de diversas culturas en su libro de 1992, Las falsificaciones de la Historia (en relación con la de España). 
dos que tiene el nombre de los Guallacanes, pasaban las mayores miserias y necesidades, y que por este motivo solicitaban mi favor para que yo, lo avisase a mi gobernador asegurandole que querían bautizar sus hijos tener su cura, y trabajar rozas para sembrar maíz, yucas, ñames, algodones y todo fruto para mantenerse y beneficiarse dándoles las herramientas de hachas y machetes, pero que los habían de sacar a las orillas del río, en donde estaban prontos a fundarse cualesquiera parte que lo dispusieran mi gobernador con la condición que me esperaban con la respuesta dentro de dos meses pues estaban prontas cincuenta familias y ofrecían que dándoles este auxilio sacarían de los montes otras muchas mas que hay (AGN, 1803).

Se interpreta de este testimonio, que no obstante la complejidad básica de la organización nuclear de los habitantes de la selva, habían logrado crear estrategias de negociación política o de cohesión del poder en su contexto. Ofrecieron a la Corona lo que sabían que necesitaba, población, familias en sus fundaciones, mano de obra, asimilación de los dogmas de la fe católica; pero al mismo tiempo exigieron a cambio, territorios ribereños.

Se entiende de esta forma que el establecimiento de fronteras fue un proceso social que antes que controlar, permitió el florecimiento de la sociedad marginal. Por fuera de los márgenes de la dominación colonial (Sæther, 2005). La misma conformación de las milicias que utilizó Mier y Guerra para adentrarse al territorio Chimila es un caso con el que podemos sustentar esta afirmación. En el testimonio de la expedición que lideró en 1768 José Joaquín de Zúñiga (Castro, 2011): “catorce milicianos de las compañías de españoles y pardos, veinte y ocho naturales de los pueblos Bonda, Masinga y Mamatoc" (AGN, 1768). Al respecto Néspolo argumenta que estas actividades llevadas a cabo por milicianos mestizos, tenían el objetivo, más allá de servir a la Corona, de ganarse la calidad de vecino (Mier, 1987).

A partir de estas situaciones a los colonizadores no les quedó otra estrategia que negociar con la población selvática para seguir intentando expandir las fronteras y hacerse al dominio de estas tierras. Por su parte los españoles ofrecían antes que nada, la posibilidad de situarse en uno de sus pueblos con un cura, alcalde, policía; también la oportunidad de acceder a herramientas y animales para trabajar; hacer parte de las milicias 
rurales y urbanas con el objetivo de adquirir la categoría de vecino, lo que representaba beneficios sociales y políticos. Mientras tanto, los nativos y mestizos, también habían adquirido condiciones con las cuales pudieron negociar. Estos últimos ofrecían a los españoles, el acceso al territorio, asimilarse al sistema colonial, servir como mano de obra, más familias para asentarse en los pueblos, capturar familias que atentaban contra la gente y los pueblos fundados.

Encontré el pueblo de los Guayacanes enteramente destruido y entré el monte y solo había seis indios, los cuales con mi ida se repartieron en solicitud de los que faltaban que con efecto se juntaron sobre cuarenta fuera de mujeres, hijos y agregados, y limpiaron el plan del pueblo y me ofrecieron no salir de el y con libertad que les di firmada siguieron quince de ellos a solicitar los que han hecho las averías en el río grande, asegurándome traerlos a dicho pueblo con los demás que encuentren y de avisarme para que pase así reconocimiento en fin queden gratificados a los principales (AGN, 1801-1802).

Así, a la Corona no le quedó más opción que dejar de acercarse a estas comunidades a través de enfrentamientos violentos, más bien entraron en negociaciones que ayudaron a configurar, de manera inconsciente, un nuevo panorama social y de manera paralela, la transformación cultural de todo el territorio.

Las negociaciones iniciaron un proceso de intercambio cultural que generó el nacimiento de una sociedad con tanta fuerza, resistencia y persistencia que hoy día somos, en parte, resultado del dinamismo de esta sociedad. Aquí es donde se encuentran las raíces de la sociedad, por lo menos del Caribe colombiano actual. Somos hijos de la causalidad, y no tenemos nada que ver con la casualidad (Vidal y Luquetta, 2015, p. 45).

\section{Territorio y cultura... a manera de discusión final}

Las transformaciones que sufrió el paisaje hicieron que las comunidades nativas se insertaran en un proceso de hibridación con la población mestiza, razón por la cual, a finales del siglo xviı y a lo largo de todo el 
siglo xix, el rastro de algunas comunidades nativas como es el caso de los Chimila se hace difuso y disperso, casi invisible. Dicho fenómeno se da a partir de la necesidad de estas comunidades por subsistir. Miembros o familias de estas parcialidades se sujetaron a las imposiciones de los agentes de la Corona. Otras se opusieron a ser despojados de su territorio, pero sobre todo pusieron resistencia a dejarse llevar por los cambios que la apropiación de los espacios por parte de los colonos conllevaron, es decir, trataron de impedir que su cultura se viera trastocada por las imposiciones, ya no del sistema colonial, sino las que los procesos de mestizaje promovieron.

Es desde esta óptica que podemos adquirir la capacidad de comprender los fenómenos socioculturales que tienen lugar hoy día. Sabiendo que los orígenes de la sociedad actual tiene su nacimiento en la misma llegada del hombre a América hace más o menos 12 mil años, sin embargo es en este momento coyuntural de reformas y mestizaje que se maximiza la transformación social y cultural del Caribe. Tal y como lo afirma Marcello Carmagnani (2004):

Hay que considerar que estos territorios venían experimentando un notable incremento de la producción y de la población y se configuraba en ellos una sociedad dinámica, con potentes élites locales y regionales, con intereses sociales y políticos bien definidos y con una cultura propia que se sumaba a los elementos procedentes del mundo europeo e ibérico. En otros términos, en esta fase histórica se asiste al nacimiento de la América Latina que conocemos en la actualidad (p. 81).

Los pueblos prehispánicos que habitaban la provincia de Santa Marta tenían una cultura y una forma de vida en directa relación con la naturaleza que los rodeaba. La selva les ofrecía alimento, protección y todo lo que necesitaban para su subsistencia. En este entorno, lograron organizar sus formas de vida, se apropiaron del territorio, construyeron lugares donde vivir, estructuraron sus creencias religiosas y tomaron de la naturaleza lo necesario para su manutención.

Este modo de vida chocó radicalmente con el sistema occidental que se impuso con la conquista y que por tres siglos intentó dominarlos. Desde mediados del siglo xviı, dicho proceso se hizo más recurrente. Se llevaron 
a cabo entradas que obligaron a estas comunidades indígenas cada vez más a adentrarse al interior de la selva. Al tiempo comenzó a encontrarse e interactuar con otras comunidades no nativas, a causa de los intentos de la Corona por establecer un control más eficaz en estas tierras y por expandir las fronteras coloniales. En este sentido, las negociaciones y alianzas intensificaron el mestizaje que venía dándose desde los mismos tiempos de los contactos. De tal manera que la configuración social de toda la provincia se vio influenciada por el crecimiento demográfico de la población mestiza.

De parte de estos últimos, se ejerció una fuerte oposición, no necesariamente bélica o violenta, contra este proceso; lograron soportar la invasión de los representantes de la Corona en su territorio, sin embargo, paulatinamente se vieron obligados a ir disminuyendo su resistencia, de tal forma que floreció una nueva cultura mestiza que proporcionó en adelante — siglo xix-, la mano de obra necesaria para la explotación de un territorio muy rico en biodiversidad y por tanto, en recursos naturales.

De manera concreta, a diferencia de la selva, en las ciudades donde la presencia de la Corona era fácilmente palpable, el mestizaje se convirtió casi en un proyecto orientado por dinámicas sociales y económicas, tal vez, también políticas (López-Bejarano, 2008). En estos espacios, hubo fuerza y control de parte de los españoles. Pero más allá de las ciudades, como Santa Marta o Cartagena al norte de lo que hoy es Colombia este poder monárquico se disipaba al irse adentrando en la selva. Es decir, era un poder nuclear enfocado a las actividades comerciales y portuarias que cumplían dichas ciudades.

Más allá de las fronteras coloniales, la selva donde habitaban comunidades marginales, fue el espacio donde se configuró una nueva sociedad. Y la idea de expandir las fronteras de la Corona, causó un efecto contrario al esperado. La intención de la Corona por dominar en contraposición a lo que Marta Herrera sostiene, no fue eficaz ni logró surtir los efectos que esperaba en los valles interfluviales de Santa Marta (Herrera, 2002). Ni los pacificadores ni religiosos tuvieron la capacidad ni el músculo para reordenar las comunidades selváticas que se replegaron y exponencialmente poblaron el interior de la provincia. Distinto a los propósitos de las Reformas Borbónicas, descritos líneas atrás, las campañas de pacificación, reducción y evangelización que se implementaron en Santa 
Marta a mediados de siglo xviı dieron inicio a la sociedad que aún hoy en día manifiesta sus raíces sociales y culturales autónomas.

\section{Referencias}

Archivo General de la Nación Colombia (AGN). (1768). Expedición contra los Chimilas: diario [Sección: Colonia. Fondo]. Caciques e indios (Legajo 17, folios 966-1030). Archivo General de la Nación Colombia, Área de Contenido y Estructura.

Archivo General de la Nación Colombia (AGN). (1797-1798). Los indios Chimilas a cerca de su evangelización [Sección Colonia]. Caciques e indios (Legajo 18, D. 48, folios 788-847). Archivó General de la Nación Colombia, Área de Contenido y Estructura.

Archivo General de la Nación Colombia (AGN). (1801-1802). Caciques e indios (Legajo 36, orden 10, folios 427-442). Archivo General de la Nación Colombia, Área de Contenido y Estructura.

Archivo General de la Nación Colombia (AGN). (1803). Indios Chimilas: solicitud de tierras [Sección: Colonia. Fondo]. Caciques e indios (Legajo 14, folios 902-903). Archivo General de la Nación Colombia, Área de Contenido y Estructura.

Carmagnani, M. (2004). El otro occidente. América latina desde la invasión europea hasta la globalización. México: Fondo de Cultura Económica.

Caro, J. (1992). Las falsificaciones de la Historia (en relación con la de España). Barcelona: Seix Barral.

Castro, H. (2011). Milicias de todos los colores en el partido de Tierradentro a finales del siglo xvin. Historia Caribe, 6(19), 137-151.

Conde, J. (1999). Espacio, sociedady conflicto en la provincia de Cartagena. Barranquilla, Colombia: Fondo de publicaciones de la Universidad del Atlántico.

Daza, V. (2009). Los marqueses de Santa Coa: una historia económica del Caribe colombiano, 1750-1810. Bogotá, Colombia: Instituto Colombiano de Antropología e Historia.

Fals, O. (1979). Mompox y Loba: Historia doble de la costa. Bogotá, Colombia: Carlos Valencia Editores.

García, A. (2011). Tierra adentro, mar en fuera: el puerto de Veracruz y su litoral a Sotavento, 1519-1821. México, D.F.: Fondo de Cultura Económica.

García, V. (2015). Estado y frontera en el norte de Chile. Estudios Fronterizos, 16(31), 117-48.

González, M. D. (1978). La política de población y pacificación indígena en las poblaciones de Santa Marta y Cartagena (Nuevo Reino de Granada), 17501800. Boletín Americanista. 
Grahn, R. (1985). Contraband, commerce and society in New Granada, 1713-1763. Estados Unidos: Duke University.

Gruzinski, S. (2004). La colonización de lo imaginario Sociedades indígenas y occidentalización en el México español. Siglos XVI-XVIII. México: Fondo de Cultura Económica.

Gutiérrez, J. (2010). Los indios de la Nueva Granada y las guerras de independencia. En H. Bonilla (Ed.), Indios, negros y mestizos en la independencia (pp. 97-117). Bogotá, Colombia: Planeta.

Herrera, M. (2002). Ordenar para controlar. Ordenamiento espacial y control político en las llanuras del Caribe y en los Andes Centrales Neogranadinos Siglo XVIII. Bogotá, Colombia: Academia Colombiana de la Historia, Instituto Colombiano de Antropología e Historia.

Humboldt, A. von (1980). Diario de viaje por el Magdalena. En A. Noguera Mendoza, Crónica Grande del Río Magdalena. Bogotá, Colombia: Ediciones Sol y Luz.

Isaacs, J. (1951). Estudio sobre las tribus del Magdalena. Bogotá, Colombia: Incunables. Julián, A. (1854). La perla de América, provincia de Santa Marta: reconocida, observada y expuesta en discursos históricos. París: Thunot.

López-Bejarano, P. (2008). Dinámicas mestizas. Tejiendo en torno a la jerarquía, al trabajo y al honor. Nueva Granada, siglo xvir. Nuevo Mundo Mundos Nuevos. Recuperado de http://nuevomundo.revues.org/19263

Luquetta, D. y Vidal, A. (Febrero-agosto de 2014). La vida material del otro lado de la frontera colonial: Los pueblos Chimila en la segunda mitad del siglo xvin. Diálogos. Revista Electrónica de Historia, 15(1), 111-133.

Mier, J. M. de (1987). Historia de Colombia según sus protagonistas (Tomo I). Poblamiento en la Provincia de Santa Marta. Bogotá, Colombia: Libreros Colombianos Ltda.

Néspolo, E. (2006). La "Frontera" Bonaerense en el siglo xviII un espacio políticamente concertado: fuertes, vecinos, milicias y autoridades civilesmilitares. Mundo Agrario. Revista de estudios rurales, 7(13). Recuperado de http://www.mundoagrario.unlp.edu.ar/article/view/v07n13a08/1181

Pedraja, R. de la (1978). Los precios de los comestibles en la época del virreinato, 17401810. Bogotá: Centro de Estudios sobre Desarrollo Económico, Facultad de Economía, Universidad de los Andes.

Polo, J. (2005). Etnicidad, conflicto social y cultura fronteriza en la Guajira (17001850). Bogotá: Ministerio de Cultura.

Polo, J. (2007). La conquista del Caribe Colombiano o la pedagogía exploratoria para el establecimiento de la dominación española. En G. Bell Lemus, La región y sus orígenes. Momentos de la historia económica y política del Caribe colombiano (pp. 15-38). Barranquilla, Colombia: Parque Cultural del Caribe. 
Polo, J. y Solano, S. (2011). Historia social del Caribe colombiano: territorios, indígenas, trabajadores, cultura, memoria e historia. Medellín: La Carreta Editores.

Quarleri, L. (30 de noviembre de 2012). Políticas borbónicas en los "pueblos de indios guaraníes" estratificación, mestizaje e integración selectiva. Nuevo Mundo Mundos Nuevos. Recuperado de http://nuevomundo.revues.org/64459

Reichel-Dolmatoff, G. (1946). Etnografía Chimila. Boletín de Arqueología, 95-156.

Rosa, J. N. de la (1975). Floresta de la Santa Iglesia Catedral de la ciudad y provincia de Santa Marta. Bogotá, Colombia: Banco Popular.

Sæther, S. (2005). Identidades e independencia en Santa Marta y Riohacha, 1750 - 1850. Bogotá, Colombia: Instituto Colombiano de Antropología e Historia.

Salzedo, P. (1987). Apuntaciones Historiales de Mompox. Cartagena, España: Espitia Impresores.

Santa Gertrudis, F. J. de (1970). Maravillas de la naturaleza. Bogotá, Colombia: Banco Popular.

Trejos, L. y Luquetta, D. (2014). Una aproximación a la ilegalidad, el crimen organizado y ausencia estatal en la frontera colombo-venezolana. El caso del departamento de La Guajira en Colombia. Memorias. Revista digital de historia y arqueología desde el Caribe, (24). doi:http://dx.doi.org/10.14482/memor.24.6460

Vidal, A. y Luquetta, D. (2015). Entre ríos, llanuras y selva. Aspectos culturales de las poblaciones nativas de la provincia de la Santa Marta en la segunda mitad del xviII. Investigación y Desarrollo, 23(1), 38-57.

Ybot, A. (1952). La arteria histórica del Nuevo Reino de Granada, Cartagena-Santa Fe, 1538-1798: Los trabajadores del Río Magdalena y El Canal del Dique, según documentos del Archivo General de Indias de Sevilla. Bogotá, Colombia: Archivo General de Indias de Sevilla.

Zuluaga, M. (3 de marzo de 2010). La dominación colonial en el plural: El poder colonial y la conquista de los pueblos muiscas, paeces y Chimilas en la Nueva Granada. Nuevo Mundo Mundos Nuevos. Recuperado de http://nuevomundo. revues.org/59010 